\title{
Synthesis and Characterization of Chitosan-Polyvinyl Alcohol Blended with Cloisite 30B for Controlled Release of the Anticancer Drug Curcumin
}

\author{
Umesh Kumar Parida ${ }^{1}$, Ashok Kumar Nayak ${ }^{2}$, Birendra Kumar Binhani ${ }^{3}$, P. L. Nayak ${ }^{1^{*}}$ \\ ${ }^{1}$ P. L. Nayak Research Foundation, Neelachal Bhavan, Cuttack, India; ${ }^{2}$ P. L. Nayak Research Foundation, Neelachal Bhavan, Bidy- \\ adharpur, Cuttack, India; ${ }^{3}$ KIIT School of Biotechnology, KIIT University, Bhubaneswar, India. \\ Email: "parida.umesh@gmail.com, ashok@biolab.com,drbinhani@gmail.com, ${ }^{*}$ plnayak@rediffmail.com
}

Received May $10^{\text {th }}, 2011$; revised June 27 ${ }^{\text {th }}, 2011$; accepted July $30^{\text {th }}, 2011$.

\begin{abstract}
In the present research program, polymer nanocomposites have been used as the drug carrier for delivery systems of anticancer drug. Chitosan (CS) and Polyvinyl Alcohol (PVA) with different ratios were blended with different wt\% of Cloisite $30 B$ solution by solvent casting method. Glutaraldehyde with different wt\% was added to the blended solution as a crosslinking agent. Cloisite $30 \mathrm{~B}$ was incorporated in the formulation as a matrix material component which also plays the role of a co-emulsifier in the nanocomposite preparation. Curcumin with different concentrations were loaded with CS-PVA/C $30 B$ nanocomposites for studying the in-vitro drug delivery systems. Morphology and structure characterization of nanocomposites were investigated by fourier transmission infra red spectroscopy (FTIR), scanning electron microscope (SEM), tensile strength and water uptake capacity. The drug release was studied by changing time, $p H$ and drug concentrations. The kinetics of the drug release was studied in order to ascertain the type of release mechanism. Based on the diffusion as well as the kinetics, the mechanism of the drug release from the composite matrix has been reported.
\end{abstract}

Keywords: Chitosan, PVA, C 30B, Glutaraldehyde, Curcumin, Drug Delivery

\section{Introduction}

Carrier-mediated drug delivery has emerged as a powerful methodology for the treatment of various pathologies. The therapeutic index of traditional and novel drugs is enhanced via the increase of specificity due to targeting of drugs to a particular tissue, cell or intracellular compartment, the control over release kinetics, the protection of the active agent or a combination of the above. Polymer composites were proposed as drug carriers over 30 years ago and have received growing attention since, mainly due to their stability, enhanced loading capabilities and control over physicochemical properties [1-2]. In addition to systemic administration, localized drug release may be achieved using macroscopic drug depots close to the target site. Among various systems considered for this approach, in situ-forming biomaterials in response to environmental stimuli have gained considerable attention, due to thenon-invasive character, reduc- tion of side effects associated with systemic administration and better control over biodistribution [3]. In recent years biodegradable polymers have attracted attention of researchers to be used as carriers for drug delivery systems.

Poly(vinyl alcohol), PVA, is a non-toxic, water-soluble synthetic polymer and has good physical and chemical properties and film-forming ability [4].The use of this polymer is important in many applications such as controlled drug delivery systems, membrane preparation, recycling of polymers and packaging. Studies on the mechanism of dissolution and changes in crystallinity and swelling behaviour of PVA and its physical gel-forming capabilities, have been carried out [5]. PVA has bioinertness and it has many uses in medical applications such as artificial pancreas, hemodialysis, nanofilteration, synthetic vitreous and implantable medical device. Antithrombogenicity, cell compatibility, blood compatibility and biocompatibility of PVA have been studied exten- 
sively $[3,5,6]$.

Chitosan (Cs) is a natural polysaccharide formed during the deacetylation of chitin in alkaline condition. It comprises an unbranched chain consisting of $\beta-(1,4)-2-$ amino-2-deoxy-D-glucopyranose, and it is a unique basic linear polysaccharide [4,7-9]. The hydrophilicity of the polymer due to amine functionality in most repeat units makes the polymer soluble in dilute acid [10]. Chitosan is widely used in food and pharmaceutical industry and in biotechnology. This polysaccharide has been extensively studied in the field of biomaterials and because of its biological properties, biodegradability, bioactivity and biocompatibility it has attracted much attention [11-16]. Polymer blending is one of the useful ways to have new material with required properties and there have been great scientific and commercial progress in the area of polymer blends. This was driven by the realization that new molecules are not always required to meet the need for new materials and blending can usually be implemented more rapidly and economically than the development of new materials $[17,18]$.

Blends of synthetic and natural polymers represent a new class of materials and have attracted much attention especially in bioapplication as biomaterial. The success of synthetic polymers as biomaterial relies mainly on their wide range of mechanical properties, transformation processes that allow a variety of different shapes to be easily obtained and low production costs [2]. Biological polymers represent good biocompatibility but their mechanical properties are often poor, the necessity of preserving biological properties complicates their processability and their production costs are very high $[19,20]$. It is favorable that intermolecular interaction exists between two polymer species. Hydrophilicity of the synthetic polymers has great influence on the blend preparation and properties. Surface and bulk hydrophilicity of blended polymers affect mainly their biological behaviour. Bulk hydrophilicity of polymers may be studied by water uptake ratio, and surface hydrophilicity could be measured by surface tension and water contact angle. The PVA is a hydrophilic and water-soluble polymer and chitosan contains hydroxyl and amine groups. Some aspects, of their blend properties have been studied [21].

Cloisite 30B is methyl, tallow, bis-2 hydroxyethyl, quaternary ammonium, where tallow is $65 \% \mathrm{C} 18,30 \%$ $\mathrm{C} 16$, and $5 \% \mathrm{C} 14$. Clay minerals are widely used materials in drug products as delivery agents [22]. Montmorillonite (MMT) can provide mucoadhesive capability for the nanoparticle to cross the gastrointestinal (GI) barrier [23]. MMT is also a potent detoxifier, which belongs to the structural family of 2:1 phyllosilicate. MMT could absorb dietary toxins, bacterial toxins associated with gastrointestinal disturbance, hydrogen ions in acidosis and metabolic toxins such as steroidal metabolites associated with pregnancy [24].

Curcumin is a hydrophobic polyphenol derived from turmeric: the rhizome of the herb Curcuma longa. Chemically, it is a bis-a, b-unsaturated diketone (commonly called diferuloylmethane) that exhibits keto-enol tautomerism, having a predominant keto form in acidic and neutral solutions and a stable enol form in alkaline media. Commercial curcumin is a mixture of curcuminoids, containing approximately $77 \%$ diferuloylmethane, $18 \%$ demethoxycurcumin, and 5\% bisdemethoxycurcumin [2527]. Traditionally, turmeric and other curcuminoids have been used in therapeutic preparations for various ailments in different parts of the world. Numerous therapeutic effects of curcumin/turmeric have been confirmed by modern scientific research. Herein, we present a systematic review of the clinical and experimental data on the use of curcumin in the treatment of cancer [28]. Curcumin possesses antioxidant, anti-inflammatory, anticarcinogenic, and antimicrobial properties, and suppresses proliferation of a wide variety of tumor cells. Several clinical trials dealing with cancer have addressed the pharmacokinetics, safety, and efficacy of curcumin in humans. Despite extensive research and development, poor solubility of curcumin in aqueous solution remains a major barrier in its bioavailability and clinical efficacy. Being hydrophobic in nature, it is insoluble in water but soluble in ethanol, dimethylsulfoxide, and acetone. To increase its solubility and bioavailability, attempts have been made through encapsulation in liposomes, polymeric and lipo-NPs, biodegradable microspheres, cyclodextrin, and hydrogels [29-34].

In this study, blended films were prepared from PVA and $\mathrm{Cs}$ compounded with Cloisite $30 \mathrm{~B}$ with varying concentrations. The FTIR, SEM, mechanical and water uptake properties of these films were investigated. The blends were mixed with different amount of curcumin and the drug delivery system was investigated at different $\mathrm{pH}$ medium and the various kinetic parameters have been computed. The plausible mechanism of drug delivery has been postulated based on the kinetic data.

\section{Experimental}

\subsection{Materials}

PVA Samples was purchased from Aldrich Co. (with 99\% hydrolyzed, Mw 85,000 - 146,000). A sample of chitosan (Cs) was from India Sea Foods, Kerala, India, with $85.6 \%$ degree of deacetylation and viscosity of $115 \mathrm{cps}$ in $1 \%$ acetic acid. Cloisite 30B was procured from Southern Clay, USA. Curcumin was a generous gift from VINS 
Bioproducts, Medak, Andhra Pradesh. All other chemicals used were analytical grade.

\subsection{Methods}

The polymer films were prepared by solvent casting method. Cs solutions were prepared by dissolving chitosan in $1 \%$ aqueous acetic acid solution at room temperature with stirring. The PVA was dissolved in hot water to form $10 \mathrm{wt} \%$ polymer solutions. Both polymer solutions were filtered using sintered glass and the solutions were carefully mixed at various ratios. The weight fraction of PVA was different to obtain a series of blends with 0 to $100 \%$ wt PVA in the resulting solution as listed in Table 1.

The filtered solution was placed under vacuum and it was cast on a clean glass plate. Samples were dried at $60{ }^{\circ} \mathrm{C}$, immersed in $\mathrm{NaOH}(1 \mathrm{~N})$ and saturated $\mathrm{Na}_{2} \mathrm{SO}_{4}$ to remove residual materials then washed with deionized water to remove alkali and unreacted materials and finally dried at $60^{\circ} \mathrm{C}$ for $24 \mathrm{~h}$. For cross-linking of the films a specific amount of glutaraldehyde was added to the solution, mixed thoroughly and it was cast as above.

\subsection{Drug Loading}

Curcumin-loaded Cs-PVA/ C 30B nanocomposites were prepared by emulsion/solvent evaporation method. In short, curcumin of different loadings, i.e., $1 \mathrm{wt} \%, 3 \mathrm{wt} \%$, $5 \mathrm{wt} \%, 7 \mathrm{wt} \%$ and $10 \mathrm{wt} \%$ were dissolved in ethanol with $(80: 20) \mathrm{Cs}-\mathrm{PVA} / \mathrm{C} 30 \mathrm{~B}$. The formed solution was poured into a labeled petri dish and allowed to evaporate the solvent overnight at room temperature. This compound was used for drug delivery purposes.

\subsection{Dissolution Experiments}

Dissolution experiments were performed at $37^{\circ} \mathrm{C}$ using the dissolution tester (Disso test, Lab India, Mumbai, India) equipped with six paddles at a paddle speed of 100 rpm. About $900 \mathrm{ml}$ of phosphate buffer solution (pH 1.2 and 7.4) was used as the dissolution media to stimulate gastrointestinal tract (GIT) conditions. A $5 \mathrm{ml}$ aliquot was used each time for analyzing the curcumin content at a fixed time interval. The dissolution media was replenished with a fresh stock solution. The amount of curcumin released was analyzed using a UV spectrophotometer (Systronics, India) at the $\lambda_{\text {max }}$ value of $490 \mathrm{~nm}$.

\subsection{Drug Release Mechanism from Matrices}

From time to time, various authors have proposed several types of drug release mechanisms from matrices. It has been proposed that drug release from matrices usually implies water penetration in the matrix, hydration, swelling, diffusion of the dissolved drug (polymer hydro fu-
Table 1. The ratio of poly (vinyl alcohol) (PVA), chitosan (Cs) and the amount of glutaraldehyde (GA) in different samples.

\begin{tabular}{cccc}
\hline Sample & Cs (wt\%) & $\begin{array}{c}\text { PVAL } \\
(\mathbf{w t} \%)\end{array}$ & $\begin{array}{c}\text { GA } \times \mathbf{~ 1 0}^{-5} \\
(\mathbf{m o l} / \mathbf{g} \text { polymer })\end{array}$ \\
\hline $\mathrm{S} 1$ & 100 & 0 & 0 \\
$\mathrm{~S} 1\left(\mathrm{GA}_{1}\right)$ & 100 & 0 & 2.4 \\
$\mathrm{~S} 2$ & 75 & 25 & 0 \\
$\mathrm{~S} 2\left(\mathrm{GA}_{1}\right)$ & 75 & 25 & 2.4 \\
$\mathrm{~S} 3$ & 50 & 50 & 0 \\
$\mathrm{~S} 3\left(\mathrm{GA}_{1}\right)$ & 50 & 50 & 2.4 \\
$\mathrm{~S} 3\left(\mathrm{GA}_{2}\right)$ & 50 & 50 & 5 \\
$\mathrm{~S} 3\left(\mathrm{GA}_{3}\right)$ & 50 & 50 & 7.5 \\
$\mathrm{~S} 4$ & 25 & 75 & 0 \\
$\mathrm{~S} 4\left(\mathrm{GA}_{1}\right)$ & 25 & 75 & 2.4 \\
$\mathrm{~S}$ & 0 & 100 & 0 \\
$\mathrm{~S} 5\left(\mathrm{GA}_{1}\right)$ & 0 & 100 & 2.4 \\
\hline
\end{tabular}

sion), and/or the erosion of the gelatinous layer. Several kinetic models relating to the drug release from matrices, selected from the most important mathematical models, are described over here. However, it is worth mention that the release mechanism of a drug would depend on the dosage from selected, $\mathrm{pH}$, nature of the drug and, of course, the polymer used.

1) Zero - Order Kinetics [35].

$$
W=k_{1} t
$$

2) First - Order Kinetics $[35,36]$.

$$
\ln (100-W)=\ln 100-k_{2} t
$$

3) Hixon-Crowel's Cube- Root Equation (Erosin Model) [36].

$$
(100-W)^{1 / 3}=100^{1 / 3}-k_{3} t
$$

4) Higuchi's Square Root of Time Equation (Diffusion Model) [37].

$$
W=k_{4} t
$$

5) Power Law Equation (Diffusion/ Relaxation model) [38].

$$
M t / M_{\infty}=k_{5} t^{n}
$$

$\mathrm{Mt} / \mathrm{M}_{\infty}$ is the fractional drug release into dissolution medium and $\mathrm{k}_{5}$ is a constant incorporating the structural and geometric characteristics of the tablet. The term ' $n$ ' is the diffusional constant that characterizes the drug release transport mechanism. When $\mathrm{n}=0.5$, the drug diffused and released from the polymeric matrix with a quasi-Fickian diffusion mechanism. For $\mathrm{n}>0.5$, an anomalous, non-Fickian drug diffusion occurs. When $\mathrm{n}=$ 1, a non-Fickian, case II or Zero - order release kinetics could be observed. 


\section{Characterization}

\subsection{Fourier Transmission Infra Red Spectroscopy (FTIR)}

The FTIR spectrum of the chitosan, alginate, and chitosan-PVA blend was obtained using a BIORAD-FTS-7PC type FTIR spectrophotometer.

\subsection{Scanning Electron Microscopy (SEM)}

The blending of the Chitosan-PVA composites containing different concentrations was characterized using SEM (440, Leica Cambridge Ltd., Cambridge, UK). The powdered specimens were placed on the Cambridge standard aluminium specimen mounts (pin type) with double-sided adhesive electrically conductive carbon tape (SPI Supplies, West Chester, PA). The specimen mounts were then coated with $60 \%$ Gold and $40 \%$ Palladium for 30 seconds with $45 \mathrm{~mA}$ current in a sputter coater (Desk II, Denton Vacuum, Moorestown, NJ). The coated specimens were then observed on the SEM using an accelerating voltage of $20 \mathrm{kV}$ at a tilt angle of $30^{\circ}$ to observe the microstructure of the chitosan-PVA composite blends.

\subsection{Tensile Properties}

All the samples were prepared as thin films and their tensile strength and tensile strain in the dry and wet states were carried out using an Instron (model 5566, V $=5$ $\mathrm{mm} / \mathrm{min}$ and $\mathrm{d}=10 \mathrm{~mm}$ ). For testing in wet state, all the films were placed in phosphate buffer saline (PBS) solution $(\mathrm{pH}=7.2-7.4)$ for $30 \mathrm{~min}$ and then their tensile strength and tensile strain were measured. Film strips in specific dimensions and free from air and bubble or physical imperfection were held between two clamps positioned at a distance $10 \mathrm{~mm}$. During measurement, the sample was pulled by top clamp at a rate $5 \mathrm{~mm} / \mathrm{min}$. The thickness of the film sample was measured using a micrometer at five locations (center and four corners), and the mean thickness was calculated. Samples with air bubbles, nicks or tears and having mean thickness variation of greater than 5\% were excluded from analysis.

\subsection{Water Uptake}

Water absorption of the polymer-drug conjugates was measured following ASTM D 570-81. The samples were preconditioned at $50^{\circ} \mathrm{C}$ for $24 \mathrm{~h}$ and then cooled in a desiccator before being weighed. The preconditioned samples were submerged in distilled water at $25^{\circ} \mathrm{C}$ for $24 \mathrm{~h}$. The samples were removed and dried with a paper towel before weighing. Water absorption was calculated as a percentage of initial weight. The soluble material loss was checked by weighting the specimens after drying them in an oven at $50^{\circ} \mathrm{C}$ for another $24 \mathrm{~h}$. The total water absorption for $24 \mathrm{~h}$ was calculated including the soluble material loss

$$
\% \text { Swelling }=\frac{W_{1}-W_{2}}{W_{2}} \times 100
$$

where, $\mathrm{W}_{1}=$ Weight of swollen composite after $24 \mathrm{hr}$., $\mathrm{W}_{2}=$ Weight of dry composite.

\section{Results and Discussion}

\subsection{Fourier Transmission Infrared Spectroscopy (FTIR)}

FTIR spectroscopy was used to assess the polymer chemical groups (chitosan and PVA) and investigating the formation of crosslinked networks from the blends with glutaraldehyde. Figure 1A shows the FTIR spectra relative to the chitosan, PVA and [Cs/PVA] blends. Figure 1A-a spectrum of pure chitosan shows peaks around 893 and $1156 \mathrm{~cm}^{-1}$ corresponding to saccharide structure [19]. In spite of several peaks clustering in the amide II peak range from 1510 to $1570 \mathrm{~cm}^{-1}$, there were still strong absorption peaks at 1658 and $1322 \mathrm{~cm}^{-1}$, which are characteristic of chitosan and have been reported as amide I and III peaks, respectively. The sharp peaks at 1383 and $1424 \mathrm{~cm}^{-1}$ were assigned to the $\mathrm{CH}_{3}$ symmetrical deformation mode. The broad peak at 1030 and $1080 \mathrm{~cm}^{-1}$ indicates the $\mathrm{C}-\mathrm{O}$ stretching vibration in chitosan. Another broad peak at $3447 \mathrm{~cm}^{-1}$ is caused by amine N-H symmetrical vibration, which is used with $1650 \mathrm{~cm}^{-1}$ for quantitative analysis of deacetylation of chitosan. Peaks at 2800 and $2900 \mathrm{~cm}^{-1}$ are the typical C-H stretch vibrations [5]. The IR spectra of the Cs/PVA blended films presented in Figure 1A(b), Figures 1A(c) and $\mathbf{A ( d )}$ are different from that of the chitosan because of the ionization of the primary amino groups. There are two distinct peaks at 1408 and $1548-1560 \mathrm{~cm}^{-1}$. Formation of the $1548-1560 \mathrm{~cm}^{-1}$ peak is the symmetric deformation of $\mathrm{NH}_{3}$ resulting from ionization of primary amino groups in the acidic medium whereas the peak at $1408 \mathrm{~cm}^{-1}$ indicates the presence of carboxylic acid in the polymers. The peaks at $1700-1725 \mathrm{~cm}^{-1}$ are characteristic of the carboxylic acid. In the present study, the presence of carboxylic dimmer was due to the acetic acid used for dissolving the chitosan [6]. The peak at $1210-1300 \mathrm{~cm}^{-1}$ is due to the $\mathrm{C}=\mathrm{H}$ vibration.

Hence, there is a significant reduction of intensities from the main absorption bands related to chitosan, for instance amine region $\left(1500-1650 \mathrm{~cm}^{-1}\right)$, as its content was decreased from 100\% (pure chitosan, Figure 1A-a), 75\% (Figure 1A(b)), 50\% (Figure 1A(c)), 25\% (Figure 1A(d)) and $0 \%$ (pure PVA, Figure 1A(e)). The FTIR 
spectrum of pure PVA is shown in Figure 1A(e), where all major peaks related to hydroxyl and acetate groups were observed. More specifically, the broad band observed between 3550 and $3200 \mathrm{~cm}^{-1}$ is associated with the stretching $\mathrm{O}-\mathrm{H}$ from the intermolecular and intramolecular hydrogen bonds. The vibrational band observed between 2840 and $3000 \mathrm{~cm}^{-1}$ refers to the stretching $\mathrm{C}=\mathrm{H}$ from alkyl groups and the peaks between 1750 and $1735 \mathrm{~cm}^{-1}$ are due to the stretching $\mathrm{C}=\mathrm{O}$ and $\mathrm{C}-\mathrm{O}$ from acetate group remaining from PVA (saponification reaction of polyvinyl acetate) [4]. Figure 1B shows the FTIR spectra of Cs/PVA blend with a proportion of $25 \%$ Chitosan and 75\% PVA (curve-a), at two concentrations of GA chemical crosslinker, $1 \%$ (curve-b) and 5\% (curvec). It can be noted the bands at 1110, 1406, 1638 and $1650 \mathrm{~cm}^{-1}$ mainly associated with PVA, and also the presence of peaks related to carboxylic acid and the imines formed by the crosslinking reaction by glutaralde- hyde of amine groups from chitosan. Moreover, an increase in the intensity and a shift in the band associated with the bend vibration of the $\mathrm{CH}_{2}\left(1406 \mathrm{~cm}^{-1}\right)$ group was observed. As expected, because the blend crosslinking reaction was conducted at $\mathrm{pH}(4.00 \pm 0.05)$, covalent chemical bonds have preferentially occurred in the chitosan amine groups and less in the PVA hydroxyl groups [7]. Chemical crosslinking of the chitosan/PVA blends can be explained by the Schiff base formation as verified by the 1634 and $1550 \mathrm{~cm}^{-1}$ bands associated with the $\mathrm{C}=\mathrm{N}$ and $\mathrm{NH}_{2}$ groups, respectively [8]. All chitosanderived blends have shown a relative increase on their imine band and simultaneous drop on the amine $\left(-\mathrm{NH}_{2}\right)$ band after chemical crosslinking with glutaraldehyde [19]. The imine group was formed by the nucleophilic reaction of the amine from chitosan with the aldehyde. Figure 1C shows the evolution of imine groups as the glutaraldehyde concentration is increased. The PVA re-

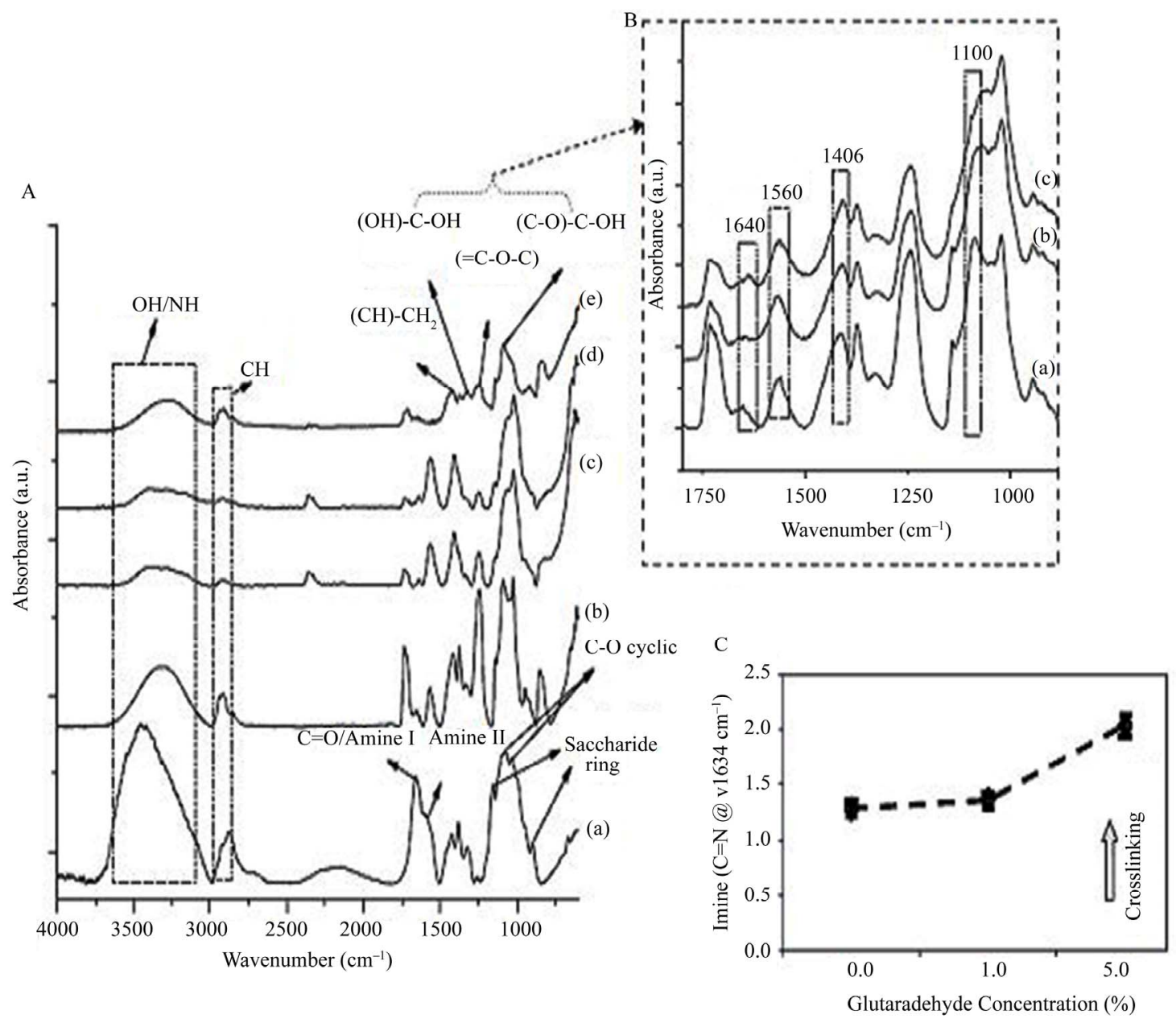

Figure 1. FTIR spectra of (a) the chitosan, (b) Cs/PVA/GA (1:3:0), (c) Cs/PVA/GA (1:1:0), (d) Cs/PVA/GA (:3:1:0), (e) PVA, (B) FTIR spectra of Cs/PVA (1:3) bands without Chemical crosslinking (a) and chemical crosslinking with $1 \%$ (b) and $5 \%$ (c), (C) Evolution of vibration band from imine group $(C=N)$ with the concentration of glutaraldehyde. 
action with GA resulted in significant alterations in the bands regarding to hydroxyls $(\mathrm{O}-\mathrm{H})$, normally associated with the acetal bridge formation [8].

\subsection{Scanning Electron Microscope (SEM)}

Figure 2 shows the surface area SEM images of chitosan-PVA and chitosan-PVA/ C 30B membranes. No obvious agglomeration of $\mathrm{C} 30 \mathrm{~B}$ particles was observed in Figures 4(a) and (b), which contain $1 \%$ and $2.5 \%$ of $\mathrm{C}$ $30 \mathrm{~B}$ respectively, thus suggesting that $\mathrm{C} 30 \mathrm{~B}$ particle can be well dispersed in chitosan-PVA matrix and the fabricated membrane can be considered as homogenous and dense with no obvious phase separation. However, in case of Figure $4(\mathrm{c})$, containing $5 \%$ of $\mathrm{C} 30 \mathrm{~B}$, the agglomeration of various sizes of $\mathrm{C} 30 \mathrm{~B}$ particles which randomly dispersed within the chitosan-PVA matrix are observed. Due to the randomness of particle distribution, chitosan-PVA/C 30B (5\%) can be regarded as quasi homogenous.

\subsection{Tensile Properties}

The tensile testing provides an indication of the strength and elasticity of the films, which can be reflected by strength and strain-at-break. The tensile strength and strain- at-break of different samples in dry and wet states were measured with Instron (Table 2). Blending ( $\mathrm{p}<$
0.05) improved tensile strength of PVA-Cs blend in dry and wet states significantly. These results indicate that blend films have higher tensile strength than pure Cs and PVA films. Blending leads to an intermolecular interaction between two polymers and this improves mechanical strength of the blends. Kim and other research workers $[7,8]$ have also supported these results. Due to possibility of interaction between $-\mathrm{OH}$ and $-\mathrm{NH}_{2}$ groups in these two polymers, blending improves mechanical properties of the films. As it can be seen in Table 2, the tensile strength of $\mathrm{S} 1$ sample is $57.2 \mathrm{MPa}$ which increases to 76.2 $\mathrm{MPa}$ for S2 sample (with $25 \mathrm{wt} \%$ PVA) and for S3 sample (with $50 \mathrm{wt} \%$ PVA ) increases to $71.6 \mathrm{MPa}$. PVA Sample has more elongation-at-break, so with increasing the PVA content in the blend, the flexibility of the films were increased.

Cross-linking with glutaraldehyde improves tensile strength and decreases tensile strain of the blend films. By increasing glutaraldehyde concentration, the films become more rigid and show less flexibility. It was found that the cross-linking improves mechanical properties of Cs as compared to PVA. The effect of glutaraldehyde to improve tensile strength increases by increasing Cs content in the blend films. The crosslinking of S2 sample (25 wt $\%$ PVA) increased tensile strength by $20 \%$ in dry

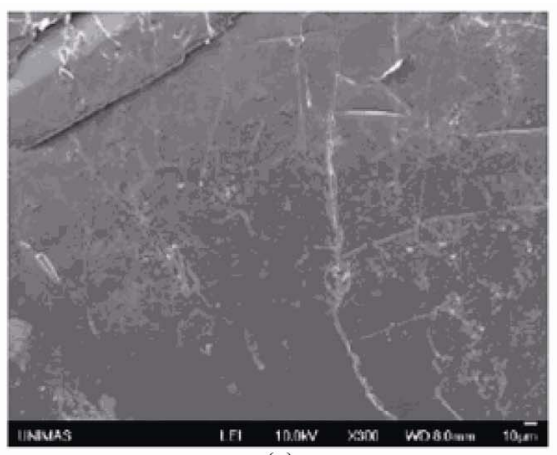

(a)

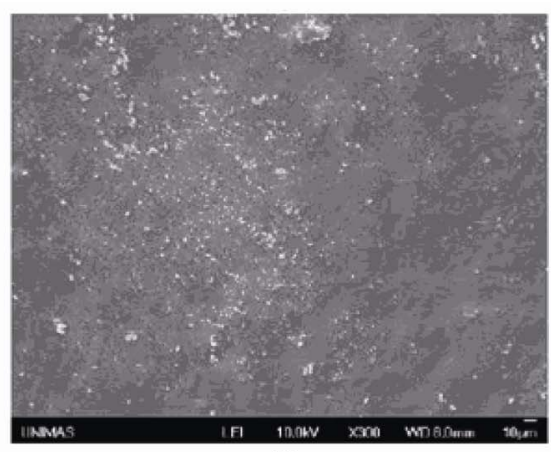

(b)

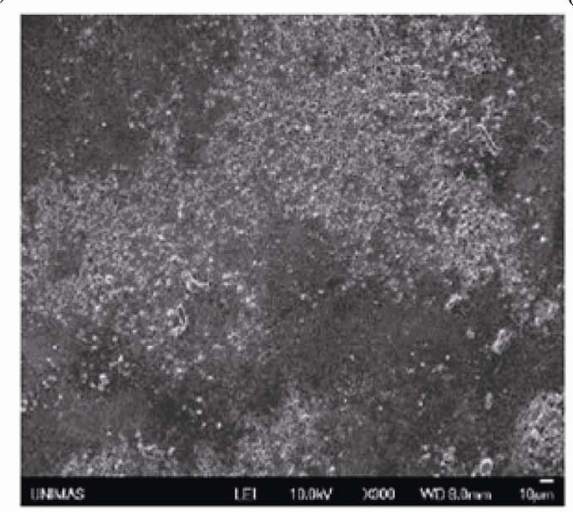

(c)

Figure 2. SEM of chitosan/ PVA with (a) 1\% C 30B, (b) $2.5 \%$ C $30 \mathrm{~B}$ and (c) $5 \%$ C $30 \mathrm{~B}$. 
Table 2. Tensile strength and tensile strain -at-break for different samples.

\begin{tabular}{|c|c|c|c|c|}
\hline \multirow[t]{2}{*}{ Sample } & \multicolumn{2}{|c|}{ Tensile Dry } & \multicolumn{2}{|c|}{ Tensile Wet } \\
\hline & Strength $(\mathrm{MPa})$ & Strain $(\%)$ & Strength (MPa) & Strain $(\%)$ \\
\hline S1 & $57.2 \pm 1.6$ & $9.0 \pm 1.0$ & $15.8 \pm 1.1$ & $40.9 \pm 2.5$ \\
\hline $\mathrm{S} 1\left(\mathrm{GA}_{1}\right)$ & $71.4 \pm 1.3$ & $7.5 \pm 0.8$ & $21.6 \pm 1.6$ & $31.7 \pm 3.6$ \\
\hline $\mathrm{S} 2$ & $78.2 \pm 1.1$ & $10.0 \pm 0.8$ & $23.4 \pm 1.7$ & $48.1 \pm 2.9$ \\
\hline $\mathrm{S} 2\left(\mathrm{GA}_{1}\right)$ & $91.2 \pm 1.9$ & $8.9 \pm 1.2$ & $31.5 \pm 1.3$ & $39.2 \pm 3.1$ \\
\hline S3 & $71.6 \pm 1.5$ & $11.2 \pm 1.4$ & $19.0 \pm 1.8$ & $55.6 \pm 3.7$ \\
\hline $\mathrm{S} 3\left(\mathrm{GA}_{1}\right)$ & $83.9 \pm 2.3$ & $10.0 \pm 1.2$ & $24.1 \pm 1.4$ & $46.5 \pm 4.1$ \\
\hline $\mathrm{S} 3\left(\mathrm{GA}_{2}\right)$ & $95.3 \pm 2.0$ & $8.2 \pm 0.9$ & - & - \\
\hline $\mathrm{S} 3\left(\mathrm{GA}_{3}\right)$ & $113.7 \pm 1.2$ & $4.1 \pm 1.1$ & - & - \\
\hline S4 & $67.1 \pm 1.1$ & $14.8 \pm 1.6$ & $16.1 \pm 1.3$ & $68.0 \pm 3.1$ \\
\hline $\mathrm{S} 4\left(\mathrm{GA}_{1}\right)$ & $76.7 \pm 1.4$ & $13.3 \pm 1.1$ & $19.3 \pm 1.5$ & $63.2 \pm 2.9$ \\
\hline S5 & $53.3 \pm 1.9$ & $16.2 \pm 1.1$ & $8.0 \pm 1.5$ & $80.1 \pm 2.5$ \\
\hline $\mathrm{S} 5\left(\mathrm{GA}_{1}\right)$ & $58.1 \pm 2.5$ & $15.4 \pm 0.9$ & $9.2 \pm 1.0$ & $76.1 \pm 1.9$ \\
\hline
\end{tabular}

state and $36 \%$ in wet state. This percentages for S4 samples ( $75 \%$ wt PVA), in the dry and wet states were $13 \%$ and $20 \%$, respectively. Similar trend was observed in the wet state. The cross-linking of chitosan and PVA with glutaraldehyde is shown in Figure 3.

\subsection{Water Uptake}

As shown in Table 3 water uptake of all samples were increased by increasing the PVA content. This is attributed to the increasing of hydrophilic groups $(-\mathrm{OH})$ in the blends. Cross-linking with GA decreases water uptake in all samples. By increasing GA concentration more hydroxyl and amino groups of polymers in the blends are consumed due to the cross-linking reactions and blends showing less capability for hydrogen bonding. The effect of $\mathrm{pH}$ on water uptake was also studied. The water uptake increased when $\mathrm{pH}$ decreased. The effect of $\mathrm{pH}$ on increasing water uptake is more significant for samples with more Cs content (Figure 4). The effect of $\mathrm{pH}$ on water uptake was decreased by increasing GA concentration (Figure 5). This could be explained by the fact that in acidic medium the amino groups of $\mathrm{Cs}\left(-\mathrm{NH}_{2}\right)$ are protonized $\left(-\mathrm{NH}_{3}{ }^{+}\right)$so that the hydrogen bonds between Cs and PVA are inhibited, therefore, the network has more potential for hydrogen bonding with surrounding water. Also, Cs molecules in the acidic condition are being uncoiled and form rods [3], which, might be another parameter to enhance hydrogen bonding with water. It seems likely that $\mathrm{pH}$ has more effect to increase water uptake for Cs in comparison with PVA.

\section{In-Vitro Drug Release}

\subsection{Effect of $\mathbf{p H}$, Time and Drug loading}

In order to investigate the effect of $\mathrm{pH}$ on the swelling of Cs-PVA/C 30B composite (2.5\%), we have measured the
$\%$ cumulative release in both $\mathrm{pH} 1.2$ and 7.4 media. $\mathrm{Cu}$ mulative release data presented in Figure 6 indicate that by increasing the $\mathrm{pH}$ from 1.2 to 7.4 , a considerable increase in the cumulative release is observed for all composites. From Figures 6(a) and (b), it is seen that the $50 \%$ drug-polymer composites have shown longer drug release rates than the other composites. Thus, drug release depends upon the nature of the polymer matrix as well as $\mathrm{pH}$ of the media. This suggests that the drugs in the blend can be used to be suitable for the basic environment of the large intestine, colon, and rectal mucosa for which there are different emptying times.

Interestingly, more than $90 \mathrm{wt} \%$ curcumin is released from composites at $\mathrm{pH} 7.4$ within 14 hours, whereas less than $80 \mathrm{wt} \%$ of the drug is released at $\mathrm{pH} 1.2$ within 14 hours. This suggests that the drugs in the composites can be used to be suitable for the basic environment. Further the electrostatic interaction of composites is more easily broken at $\mathrm{pH} 7.4$ than at $\mathrm{pH} 1.2$, leading to curcumin being released more rapidly at $\mathrm{pH} 7.4$ than $\mathrm{pH} 1.2$.

Release data (Figure 6) showed that formulations containing highest amount of drug (50\%) displayed fast and higher release rates than those formulations containing a small amount of drug loading. The release rate becomes quite slower at the lower amount of drug in the matrix, due to the availability of more free void spaces through which a lesser number of drug molecules could transport.

\section{Drug Release Kinetics}

Drug release kinetics was analyzed by plotting the cumulative release data vs. time by fitting to an exponential equation of the type as represented below [33].

$$
M t / M_{\infty}=k t^{n}
$$




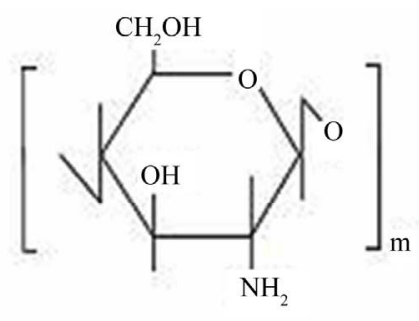

$\begin{array}{ccc}\mathrm{H}=\mathrm{C}-\mathrm{R} & =\mathrm{C}-\mathrm{H} \\ \text { II } & \text { II } \\ \mathrm{O} & \mathrm{O}\end{array}$
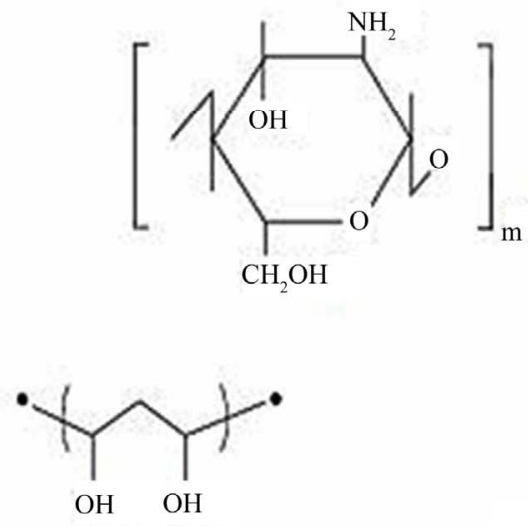

Poly (vinyl alcohol)

$\mathrm{OHCCH}_{2} \mathrm{CH}_{2} \mathrm{CH}_{2} \mathrm{CHO}$

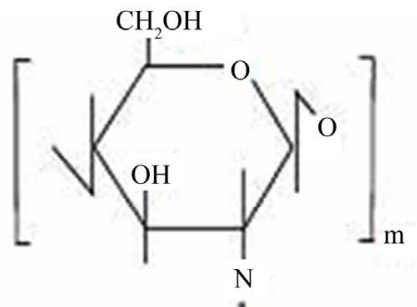

$\stackrel{\mathrm{CH}}{\mathrm{C}}$
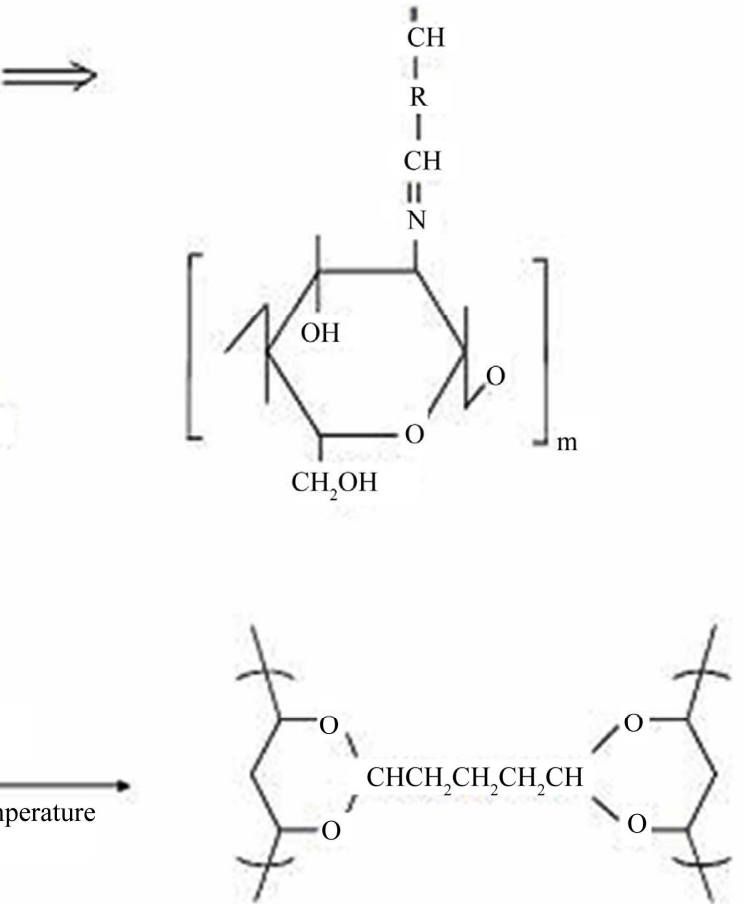

Figure 3. Schematic representation for cross-linking reaction of chitosan with GA and crosslinking reaction of PVA with GA.

Table 3. Water uptake at pH $7\left(1\right.$ hour at $\left.37^{\circ} \mathrm{C}\right)$ for different samples.

\begin{tabular}{cc}
\hline Sample & Water Uptake $(\mathrm{U} \%)$ \\
\hline $\mathrm{S} 1$ & $225 \pm 20$ \\
$\mathrm{~S} 1\left(\mathrm{GA}_{1}\right)$ & $115 \pm 18$ \\
$\mathrm{~S} 2$ & $261 \pm 31$ \\
$\mathrm{~S} 2\left(\mathrm{GA}_{1}\right)$ & $187 \pm 21$ \\
$\mathrm{~S} 3$ & $295 \pm 17$ \\
$\mathrm{~S} 3\left(\mathrm{GA}_{1}\right)$ & $230 \pm 25$ \\
$\mathrm{~S} 3\left(\mathrm{GA}_{2}\right)$ & $189 \pm 16$ \\
$\mathrm{~S} 3\left(\mathrm{GA}_{3}\right)$ & $140 \pm 13$ \\
$\mathrm{~S} 4$ & $330 \pm 15$ \\
$\mathrm{~S} 4\left(\mathrm{GA}_{1}\right)$ & $250 \pm 21$ \\
$\mathrm{~S} 5$ & $358 \pm 19$ \\
$\mathrm{~S} 5\left(\mathrm{GA}_{1}\right)$ & $308 \pm 16$ \\
\hline
\end{tabular}



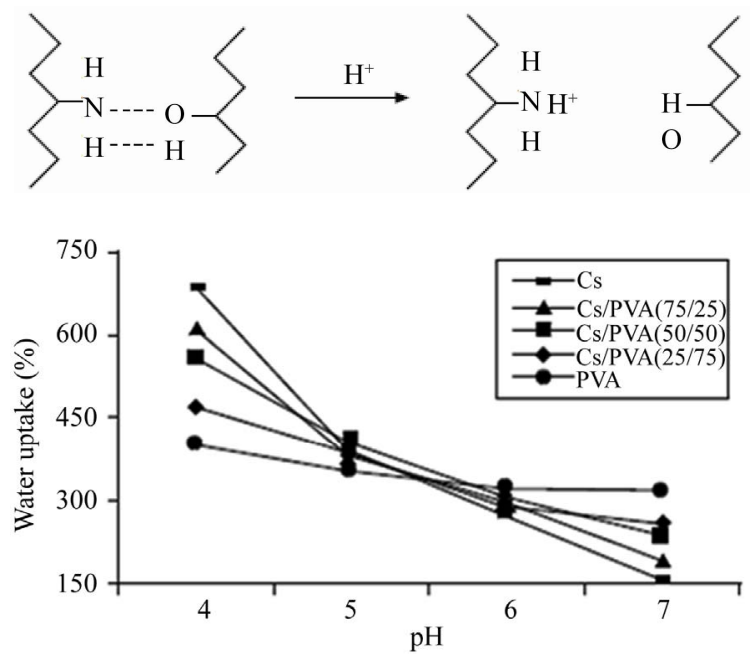

Figure 4. The effect of $\mathrm{pH}$ on water uptake for different crosslinked (GA $=2.4 \times 10^{-5} \mathrm{~mol} / \mathrm{g}$ polymer) samples.

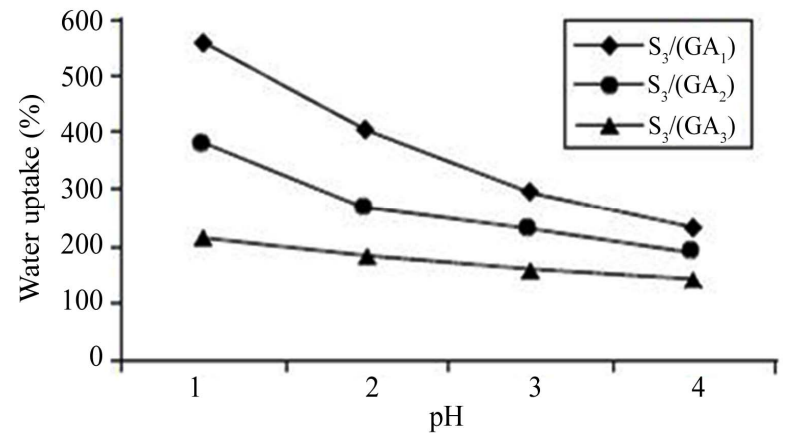

Figure 5. The effect of glutaraldehyde concentrations $\left(G A_{1}\right.$ $\left.=2.4, \mathrm{GA}_{2}=5, \mathrm{GA}_{3}=7.5\right) \times 10^{-5} \mathrm{~mol} / \mathrm{g}$ polymer) and $\mathrm{pH}$ on water uptake for S3 (Cs/ PVA -50/50) sample.

Here, $M t / M_{\infty}$ represents the fractional drug release at time $\mathrm{t}, \mathrm{k}$ is a constant characteristic of the drug-polymer system and $\mathrm{n}$ is an empirical parameter characterizing the release mechanism. Using the least squares procedure, we have estimated the values of $\mathrm{n}$ and $\mathrm{k}$ for all the five formulations and these data are given in Table 4. The values of $\mathrm{k}$ and $\mathrm{n}$ have shown a dependence on the \% drug loading and polymer content of the matrix. Values of ' $\mathrm{k}$ ' for composites prepared by varying the amounts of drug containing and keeping Cs-PVA/C 30B (2.5 wt\%) constant, ranged from 0.04 to 0.26 in $\mathrm{pH} 7.4$ and 0.03 to 0.16 in $\mathrm{pH} 1.2$ respectively. However, the drug-loaded composites exhibited ' $\mathrm{n}$ ' values ranging from 0.66 to 1.77 in $\mathrm{pH} 7.4$ and 0.61 to 1.69 in $\mathrm{pH} 1.2$ (Table 4), indicating a shift from erosion type release to a swelling controlled, non-Fickian type mechanism. The values of $n$ more than 1 have also been recently reported [36,39]. This may be due to a reduction in the regions of low mi-
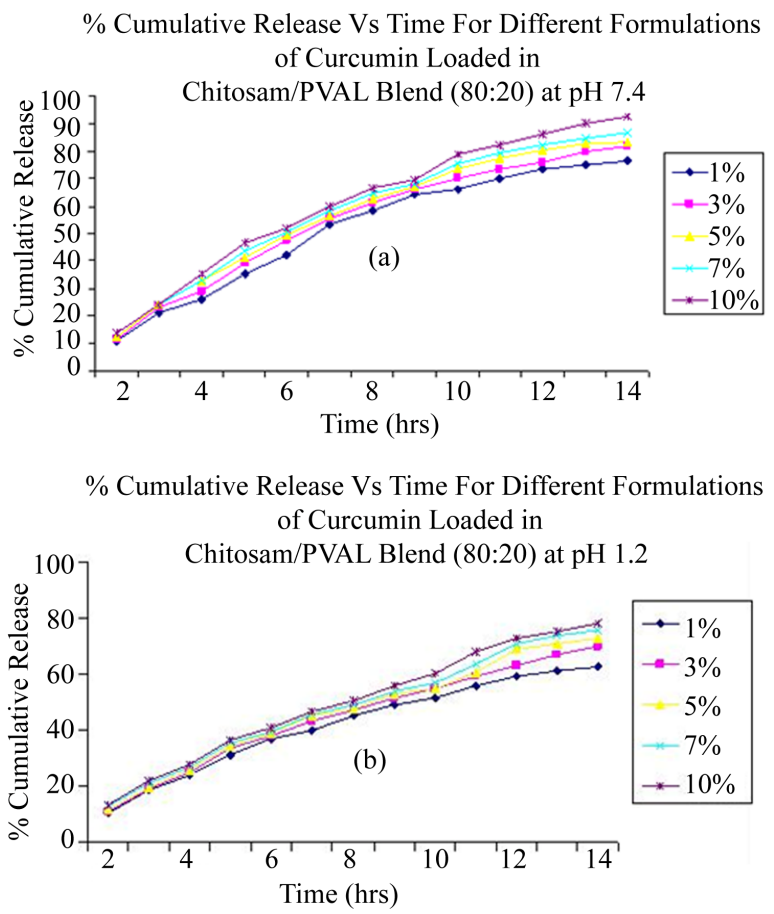

Figure 6. \% Cumulative release Vs. time for different formulation of curcumin loaded in Cs-PVA/C 30B composite film in (A) pH 7.4 and (B) pH 1.2 media.

cro viscosity inside the matrix and closure of microcavities during the swollen state of the polymer. Similar findings have been found elsewhere, wherein the effect of different polymer ratios on dissolution kinetics was investigated [40].

\section{Conclusions}

A number of research workers have reported the use of chitosan-PVAL for drug delivery for which references have been cited in the text. A survey of literature reveals that nobody has used chitosan-PVAL blended with Cloisite $30 \mathrm{~B}$ ( a nano particle) as a carrier for controlled release of curcumin. The blending of PVA and chitosan (Cs) improves tensile strength and flexibility of blended films both in dry and wet states. Cross-linking with glutaraldehyde improves tensile strength and decreases elongation of blends. Cross-linking effect of glutaraldehyde increases by increasing the Cs content. As the bulk and surface hydrophilicity of biomaterials are very important parameter for bioapplication, we studied the effect of component content, cross-linking and $\mathrm{pH}$ on water uptake, contact angle and surface tension of different blended samples. With increasing PVA content in the blends, water uptake increases. Cross-linking of the blend with glutaraldehyde decreases water uptake. The water uptake increases when $\mathrm{pH}$ decreased. 
Table 4. Release kinetics parameters of different formulations at $\mathrm{pH} 7.4$ and $\mathrm{pH} 1.2$.

\begin{tabular}{|c|c|c|c|c|c|c|}
\hline \multirow{2}{*}{$\begin{array}{c}\text { Sample } \\
\text { Code }\end{array}$} & \multicolumn{2}{|c|}{ Values of "k" } & \multicolumn{2}{|c|}{ Values of "n" } & \multicolumn{2}{|c|}{ Coodination Coefficient, $\mathrm{R}^{2}$} \\
\hline & $\mathrm{pH} 7.4$ & $\mathrm{pH} 1.2$ & $\mathrm{pH} 7.4$ & $\mathrm{pH} 1.2$ & $\mathrm{pH} 7.4$ & $\mathrm{pH} 1.2$ \\
\hline $1 \mathrm{wt} \%$ & 0.04 & 0.03 & 0.66 & 0.61 & 0.9453 & 0.9056 \\
\hline $3 w t \%$ & 0.06 & 0.05 & 0.79 & 0.74 & 0.9621 & 0.9231 \\
\hline $5 \mathrm{wt} \%$ & 0.08 & 0.06 & 1.52 & 1.31 & 0.9666 & 0.9385 \\
\hline $7 \mathrm{wt} \%$ & 0.18 & 0.12 & 1.63 & 1.38 & 0.9721 & 0.9714 \\
\hline $10 \mathrm{wt} \%$ & 0.26 & 0.16 & 1.77 & 1.69 & 0.9756 & 0.9720 \\
\hline
\end{tabular}

Further we have used different $\mathrm{pH}$ medium (i.e. $\mathrm{pH}$ 1.2 and $\mathrm{pH} 7.4$ ) in order to know the release behavior of drug from polymer matrices at different $\mathrm{pH}$. The effect of $\mathrm{pH}$ on increasing water uptake is more significant for samples with more Cs content and the effect of $\mathrm{pH}$ on water uptake decreases when glutaraldehyde concentration is raised. It seems likely that $\mathrm{pH}$ has more effect to increase water uptake for Cs in comparison with PVA. Water uptake in PVA-chitosann blend films can be controlled by variation of their contents, cross-linking agent and the $\mathrm{pH}$ of solution. It seems likely that, the blended films are homogeneous on both sides. Blending the PVA with Cs improves tensile strength, flexibility, bulk and surface hydrophilicity of the blended films.

The drug release was monitored by changing time, \% drug loading and $\mathrm{pH}$ of the medium. It was observed that the release was much more pronounced in the basic medium than the acidic medium. The kinetics of the drug release was investigated and based on the kinetic parameters such as " $\mathrm{k}$ " and " $\mathrm{n}$ " values the probable drug release (non-Fickian type of mechanism) has been reported.

\section{REFERENCES}

[1] D. Sahoo, S. Sahoo, P. Mohanty, S. Sasmal and P. L. Nayak, "Chitosan: A New Versatile Biopolymer for Various Applications," Designed Monomers and Polymers, Vol. 12, 2009, pp. 377-404. doi:10.1163/138577209X12486896623418

[2] S. Sahoo, A. Sasmal, R. Nanda, A. R. Phani and P. L. Nayak, "Synthesis of Chitosan-Poly Bhisek Sasmal, Caprolactone Blend for Control Delivery of Ofloxacin Drug," Carbohydrate Polymers, Vol. 79, 2010, pp. 106113. doi:10.1016/j.carbpol.2009.07.042

[3] S. K. Mallapragada and N. A. Peppas, "Dissolution Nechanism of Semicrystalline Poly (Vinyl Alcohol) in Water," Journal of Polymer Science: Part B, Polymer Physics, Vol. 34, 1996, pp. 1339- 1349. doi:10.1002/(SICI)1099-0488(199605)34:7<1339::AID-P OLB15>3.0.CO;2-B

[4] T. Chandy and C. P. Sharma, "Prostaglandin E1-Immobilized Poly (Vinyl Alcohol) Blended Chitosan Membranes: Blood Compatibility and Permeability Proper- ties," Journal of Applied Polymer Science, Vol. 44, 1992, pp. 2145-2156.

[5] G. Paradossi, R. Lisi, M. Paci and V. Crescenzi, "New Hydrogels Based on Poly (Vinyl Alcohol)," Journal of. Polymer Science: Part A, Polymer. Chemistry, Vol. 34, 1996, pp. 3417-3495.

doi:10.1002/(SICI)1097-4628(19990624)72:13<1755::AI D-APP11>3.0.CO;2-R

[6] J. Jegal and K. Lee, "Nanofilteration Membranes Based on Poly (Vinyl Alcohol) and Ionic Polymers," Journal of Applied Polymer Science, Vol. 72, 1999, pp. 1755-1762. doi:10.1002/app.1992.070441210

[7] J. Mathew and M. Kodama, "Study of Blood Compatible Polymers I. Modification of Poly (Vinyl Alcohol)," $P_{O}$ lymer Journal, Vol. 24, 1992, pp. 31- 41. doi: $10.1295 /$ polymj.24.31

[8] U. Edlund, and A. C. Albertsson, "Degradable Polymer Microspheres for Controlled Drug Delivery," Advances in Polymer Science, Vol. 157, 2002, pp. 67-112. doi:10.1007/3-540-45734-8_ 3

[9] A. Rajeev-Jain, "The Manufacturing Techniques of Various Drug Loaded Biodegradable Poly (Lactide-co-Glycolide) (PLGA) Devices," Biomaterials, Vol. 21, 2000, p. 2475. doi:10.1016/S0142-9612(00)00115-0

[10] K. R. Kamath and K. Park, "Biodegradable Hydrogels in Drug Delivery," Advanced Drug Delivery Reviews, Vol. 11, 1993, pp. 59-84. doi:10.1016/0169-409X(93)90027-2

[11] A. G. Mikos, M. D. Lyman, L. E. Freed and R. Langer, "Wetting of Poly (L-Lactic Acid) and Poly (DL-Lacticco-Glycolic Acid) Foams for Tissue Culture," Biomaterials, Vol. 15, No. 1, 1994, pp. 55-58. doi:10.1016/0142-9612(94)90197-X

[12] H. S. Kas, "Chitosan: Properties, Preparation and Application to Microparticulate Systems," Journal of Microencapsulation, Vol. 14, No. 6, 1997, pp. 689-711. doi: $10.3109 / 02652049709006820$

[13] T. Chandy and C. P. Sharma, "Chitosan as a Biomaterial, Artificial Cells, Blood Substitutes," Biotechnology: An International Journal, Vol. 18, 1990, pp. 1-24.

[14] H. Fukuda, "Polyelectrolyte Complexes of Chitosan with Sodium Carboxymethylcellulose," Bulletin of the Chemical Society of Japan, Vol. 53, No. 4, 1980, pp. 837-840. doi:10.1246/bcsj.53.837

[15] Y. Kato, H. Onishi and Y. Machida, "Application of Chi- 
tin and Chitosan Derivatives in the Pharmaceutical Field," Current Pharmaceutical Biotechnology, Vol. 4, 2003, pp. 303-309. doi:10.2174/1389201033489748

[16] B. Gibbs-Jackson, "Mechanism-Based Target Identification and Drug Discovery in Cancer Research," Science, Vol. 287, 2000, pp. 1969-1973. doi:10.1126/science.287.5460.1969

[17] P. Mankad, J. Spatenka, Z. Slavik, G. Oneil, A. Chester and M. Yacoub, "Acute Effects of Cyclosporine and $\mathrm{Cr}$ EL on Endothelial Function and Vascular Smooth Muscle in the Isolated Rat-Heart," Cardiovascular Drugs and Therapy, Vol. 6, No. 1, 1992, pp. 77-83. doi:10.1007/BF00050920

[18] T. M. Aminabhavi and H. G. Naik, "Chemical Compatibility Study of Geomembranes-Sorption/Desorption, Diffusion and Swelling Phenomena," Journal of Hazardous Materials, Vol. 60, 1998, pp. 175-203. doi:10.1016/S0304-3894(98)00090-9

[19] D. Sahoo, S. Sahoo, J. Das, T. K. Dangar and P. L. Nayak, "Antibacterial Activity of Chitosan Crosslinked with Aldehydes and Blended with Cloisite 30B," NanoTrends , Vol. 10, 2011, pp. 1-9.

[20] T. Sekine, K. Yoshida, F. Matsuzaki, T. Yanaki and M. Yamaguchi, "A Novel Method for Preparing Oil-in Water-in-Oil Type Multiple Emulsions Using Organophilic Montmorillonite Clay Mineral," Journal of Surfactants and Detergents, Vol. 2, No. 3, 1999, pp. 15-309. doi:10.1007/s11743-999-0082-7

[21] A. Goel, B. A. Kunnumakkara and B. B. Aggarwal, "Curcumin as 'Curecumin' from Kitchen to Clinic (Commentary)," Biochemical Pharmacology, Vol. 75, 2008, pp. 787-809. doi:10.1016/j.bcp.2007.08.016

[22] M. N. Sreejayan-Rao, "Nitric Oxide Scanvenging by Curcuminoids," Journal of Pharmacy and Pharmacology, Vol. 49, 1997, pp. 105-107. doi:10.1111/j.2042-7158.1997.tb06761.x

[23] H. P. Ammon and M. A. Wahl, "Pharmacology of Curcuma Longa," Planta Medica, Vol. 57, 1991, pp. 1-7. doi:10.1055/s-2006-960004

[24] I. Brouet and H. Ohshima, "Curcumin, an Anti-Tumour Promoter and Antiimflammatory Agent, Inhibits Induction of Nitric Oxide Synthase in Activated Macrophages," Biochemical and Biophysical Research Communications, Vol. 206, 1995, pp. 40-533. doi:10.1006/bbrc.1995.1076

[25] M. Dikshit, L. Rastogi, R. Shukla and R. C. Srimal, "Prevention of Ischaemiainduced Biochemical Changes by Curcumin and Quinidine in the Cat Heart," Indian Journal of Medical Research, Vol. 101, 1995, pp. 31-50.

[26] M. M. Yallapu, M. Jaggi and S. C. Chauhan, “ $\beta$-Cy-clodex-Trin-Curcumin Self-Assembly Enhances Curcumin Delivery in Prostate Cancer Cells Original Research Article," Colloids and Surfaces B: Biointerfaces, Vol. 79, 2010, pp. 113- 125. doi:10.1016/j.colsurfb.2010.03.039

[27] K. Varaprasad, Y. M. Mohan, K. Vimala and K. M. Raju, "Synthesis and Characterization of Hydrogel-Silver nano-
particle-Curcumin Composites for Wound Dressing and Antibacterial Application," Journal of Applied Polymer ScIence, Vol. 121, 2011, pp. 784-796. doi:10.1002/app.33508

[28] C. V. Rao, A. Rivenson, B. Simi and B. S. Reddy, "Chemoprevention of Colon Carcinogenesis by Dietary Curcumin, a Naturally Occurring Plant Phenolic Compound," Cancer Research, Vol. 55, 1995, pp. 259-266.

[29] Y. Kiso, Y. Suzuki, N. Watanabe, Y. Oshima and H. Hikino, "Antihepatotoxic Principles of Curcuma Longa Rhizomes," Planta Medica, Vol. 49, 1983, pp. 185-187. doi:10.1055/s-2007-969845

[30] H. H. Tonnesen and J. Karlsen, "Studies on Curcumin and Curcuminoids. VI. Kinetics of Curcumin Degradation in Aqueous Solution," Z Lebensm Unters Forsch, Vol. 180, 1985, pp. 402-404.

[31] A. Kunwar, A. Barik, R. Pandey and K. I. Priyadarsini, "Transport of Liposomal and Albumin Loaded Curcumin to Living Cells; an Absorption and Fluorescence Spectroscopic Study," Biochimica et Biophysica Acta, Vol 1760, 2006, pp. 1513-1520.

[32] K. Vidyalakshmi, K. N. Rashmi, T. M. Pramod-Kumar and Siddaramaiah, "Studies on Formulation and In Vitro Evaluation of PVA/Chitosan Blend Films for Drug Delivery," Journal of Macromolecular Science w Part A: Pure and Applied Chemistry, Vol. A41, 2004, pp. 11151122. doi:10.1081/MA-200026554

[33] K. Vimala, Y. M. Mohan, K.Varaprasad, N. N. Redd, S. Ravindra, N.S.Naidu, K.M.Raju, Fabrication of Curcumin Encapsulated Chitosan-PVA Silver Nanocomposite Films for Improved Antimicrobial Activity," Journal of Biomaterials and Nanobiotechnology, Vol. 2, 2011, pp. 55-64. doi:10.4236/jbnb.2011.21008

[34] M. M. Yallapu, B. K. Gupta, M. Jaggi and S. C. Chauhan, "Fabrication of Curcumin Encapsulated PLGA Nanoparticles for Improved Therapeutic Effects in Metastatic Cancer Cells Original Research Article," Journal of Colloid and Interface Science, Vol. 351, 2010, pp. 19-29. doi:10.1016/j.jcis.2010.05.022

[35] G. Xu and H. Sunada, "Influence of Formation Changes on Drug Release Kinetics," Chemical \& Pharmaceutical Bulletin, Vol. 43, 1995, pp. 483-487.

[36] R. L. Ritger and N. A. Peppas, "A Simple Equation for Disposition of Solute Release-II," Journal of Controlled Release, Vol. 5, 1987, pp. 37-42. doi:10.1002/jps.2600521210

[37] T. Higuchi, "Mechanism of Sustained Action Medication. Theoretical Analysis of Rate of Release of Solid Drugs Dispersed in Solid Matrices," Journal of Pharmaceutical Sciences, Vol. 52, No. 12, 1963, pp. 1145-1149. doi:10.1016/S0031-6865(99)00015-1

[38] A. R. Kulkarni, K. S. Soppimath and T. M. Aminabhavi, "Controlled Release of Diclofenac Sodium from Sodium Alginate Beads Crosslinked with Glutaraldehyde," Pharmaceutica Acta Helvetiae, Vol. 74, 1999, pp. 29-36. doi:10.1016/0168-3659(87)90035-6 
[39] A.K. Singla, A. Garg and D. Aggarwal, "Paclitaxel and its formulations," International Journal of Pharmaceutics, Vol. 235, No. 1, 2002, pp. 179-192.

doi:10.1016/S0378-5173(01)00986-3
[40] A. K. Singla and M. Chawla, "Chitosan: Some Pharmaceutical and Biological Aspects - an Update," Journal of Pharmacy and Pharmacology, Vol. 53, No. 8, 2001, pp. 1047- 1067. doi:10.1211/0022357011776441 